\title{
PROGRAMA SAÚDE NA ESCOLA: DESCENTRALIZAÇÃO E RESPEITO À AUTONOMIA FEDERATIVA ${ }^{1}$
}

\author{
PROGRAMA SALUD EN LA ESCUELA: DESCENTRALIZACIÓN Y RESPETO A LA \\ AUTONOMÍA FEDERATIVA
}

\section{HEALTH AT SCHOOL PROGRAM: DECENTRALIZATION AND RESPECT FOR FEDERATIVE AUTONOMY}

\author{
Marconde Ávila BANDEIRA ${ }^{2}$ \\ Ney Cristina Monteiro OLIVEIRA ${ }^{3}$ \\ Irlanda do Socorro de Oliveira MILÉO ${ }^{4}$
}

RESUMO: Este artigo tem como objetivo abordar os elementos essenciais conceituais sobre a descentralização e respeito à autonomia federativa nas Políticas Públicas Educacionais e de Saúde no Brasil. Percebendo suas definições concretas nas publicações indexadas que dão início no decálogo de 1980 perpetuando-se com mais abertura a indo-se embora em 1990. Com abordagem de cunho qualitativa explorativa que incide em alargamento de acordo com a teoria, proporcionando hipóteses para condução amostral e espaço a ser estudado (DESLANDES; GOMES; MINAYO, 2009), balizando-se pela revisão bibliográfica no banco de dados da CAPES, IBICT, SIBI/UFPA, SciELO, Google e livros. Ambos setores (educação e saúde) destacam um enredamento para promover ações estratégicas nas políticas públicas, com ênfase nas demandas dos embates e das lutas dos movimentos de reformistas, tanto político como sanitarista. As políticas interdisciplinares e as suas dialéticas intersetoriais exigem que sua implementação se dê de forma conjunta, o que mobiliza um novo modelo de estratégico dessas políticas públicas.

PALAVRAS-CHAVE: Políticas públicas educacionais. Saúde. Descentralização. Autonomia federativa.

RESUMEN: Este artículo tiene como objeto abordar los elementos esenciales conceptuales sobre la descentralización y el respeto a la autonomía federativa en las Políticas Públicas Educacionales y de Salud en Brasil. Percibiendo sus definiciones concretas en las publicaciones indexadas que comienzan en el decálogo de 1980, perpetuando con más apertura y abandonando en 1990. Con abordaje cualitativo exploratorio que incide en alargamiento

\footnotetext{
${ }^{1}$ Este artigo é um recorte que integra o capítulo teórico de nossa pesquisa de dissertação do mestrado (PPEB/NEB/UFPA, 2019-2020).

${ }^{2}$ Universidade Federal do Pará (UFPA), Belém - PA - Brasil. Discente do Programa de Pós-graduação em Currículo e Gestão da Escola Básica, Núcleo de Estudos Transdisciplinares em Educação Básica. ORCID: https://orcid.org/0000-0001-8414-0761.E-mail: bandeira.neto77@gmail.com

${ }^{3}$ Universidade Federal do Pará (UFPA), Belém - PA - Brasil. Professora Titular do Núcleo de Estudos Transdisciplinares em Educação Básica e Professora do Programa de Pós-graduação em Currículo e Gestão da Escola Básica. Doutorado em Educação (PUC/SP). ORCID: https://orcid.org/0000-0002-8091-5213. E-mail: neycmo@ufpa.br

${ }^{4}$ Universidade Federal do Pará (UFPA), Altamira - PA - Brasil. Professora Adjunta. Doutorado em Educação (PUC/SP). ORCID: https://orcid.org/0000-0002-7075-6503. E-mail: irlanda@ufpa.br
} 
acorde con la teoría, proporcionando hipótesis para conducción de muestreo y espacio a ser estudiado (DESLANDES; GOMES; MINAYO, 2009), banalizándose por la revisión bibliográfica en el banco de datos de la CAPES, IBICT, SIBI/UFPA, SciELO, Google y libros. Ambos sectores (educación y salud) destacan un enredo para promover acciones estratégicas en las políticas públicas, con énfasis en las demandas, de ahora en adelante, de los embates de las luchas de los movimientos de reformistas tanto políticos como sanitaristas. Las políticas interdisciplinarias y sus dialécticas intersectoriales exigen que su implementación ocurra de forma conjunta, lo que moviliza un nuevo modelo de estrategia de estas políticas públicas.

PALABRAS CLAVE: Políticas públicas educacionales. Salud. Descentralización. Autonomía federativa.

ABSTRACT: This paper aims to approach the essential conceptual elements on decentralization and respect for federative autonomy in Public Education and Health Policies in Brazil. Perceiving its concrete definitions in the indexed publications that started in the 1980s, it perpetuated itself with more openness to go away in 1990. With an explorative qualitative approach that focuses on enlargement according to the theory, providing hypotheses for sample conduction and space to be studied (DESLANDES; GOMES; MINAYO, 2009), being guided by the bibliographic review in the database of CAPES, IBICT, SIBI / UFPA, SciELO, Google and books. Both sectors (education and health) highlight an entanglement to promote strategic actions in public policies, with emphasis on the demands of the struggles of both political and sanitary reform movements. Interdisciplinary policies and their intersectoral dialectics require their joint implementation, which mobilizes a new strategic model of these public policies.

KEYWORDS: Public educational policies. Health. Decentralization. Federative autonomy.

\section{Introdução}

No contexto brasileiro, mais precisamente no decálogo de 1980, a centralização e o autoritarismo, dois elementos apontados originários do período ditatorial como cerne do poder, em que com isso, a descentralização, a democratização do processo decisório e a eficiência como ações estratégicas nas políticas públicas caminhariam automaticamente acopladas aos dois primeiros elementos anteriores. Neste momento histórico, aconteceram fatos democratizantes, foram: "Reformas das instituições políticas ao longo dos anos de 1980" mais precisamente, "a retomada de eleições diretas em todos os níveis de governo a partir de 1982" e os embates para a "Constituição Federal de 1988 - recuperaram as bases federativas do Estado brasileiro, suprimidas durante a ditadura militar" (ARRETCHE, 2002, p. 26-27).

No decálogo de 1990, com a instituição estadista federativa, tendo como agenda a implementação de um ampliado programa de descentralização, mais precisamente no campo das políticas sociais. Contanto, o sincronismo histórico de ambos os momentos tem apresentado 
uma falsa ideia, de que em dado momento seria igualmente o outro, uma vez que não são. Ainda que oriundos também do contexto da história de construção da realidade brasileira, sendo indeferido o elemento autoritário e centralizador, assim como o federalismo e a descentralização, não aludem edificação de políticas públicas idênticas (ARRETCHE, 2002, p. 27).

Para tanto, neste decálogo, a reforma estadista federalista brasileira, institui-se como a prática de um ampliado programa de descentralização das políticas sociais, contemporizando as unidades federativas intermediárias e locais (estados e municípios) com maiores componentes funcionais de ações estratégicas nas políticas públicas sociais, não abonando as cautelas que assinalam para a ilusória paralisia decisória em Estados federativos.

Neste artigo, abordaremos os elementos essenciais conceituais sobre a descentralização e da autonomia federativa nas Políticas Públicas Educacionais e de Saúde no Brasil, levandose em consideração a discussão do Art. $3^{\circ}, \S 1^{\circ}$, Diretriz I. do Decreto Presidencial n 6.286/2007, que institui o Programa Saúde na Escola, como parte das agendas reformistas estadistas federalistas (BRASIL, 2007).

A abordagem é de cunho qualitativa explorativa, incide em alargamento, de acordo com a teoria para significação, e demarcação objetiva do estudo a ser explorado, proporcionando hipóteses para condução amostral e espacial a ser estudado problematizando, especificando o caminho a ser percorrido e artifícios utilizados (DESLANDES; GOMES; MINAYO, 2009).

Nos balizamos pela revisão bibliográfica, que se refere sobre a importância na qualidade litúrgica, uma vez que a mesma tem o objetivo "iluminar o caminho a ser trilhado pelo pesquisador, desde a definição do problema até a interpretação dos resultados" (ALVESMAZZOTI, 2000, p. 26). Com isso, exploramos os bancos de dados da Coordenação de Aperfeiçoamento de Pessoal de Nível Superior (CAPES), do Instituto Brasileiro de Informação em Ciência e Tecnologia (IBICT), do Sistema de Bibliotecas da Universidade Federal do Pará (SIBI/UFPA), SciELO, Google e em livros sobre o tema. Empregando os descritores: Políticas Públicas Educacionais; Saúde; descentralização e a autonomia federativa.

Após leituras dos resumos e considerações finais dos textos explorados, o que nos dirigiu aos elementos essenciais conceituais que para descentralização, elegemos: Arretche (2002), Novais e Filho (2010) e Lima (2015), e, para autonomia federativa: Arretche (2002). Oliveira, Barbosa e França (2013), Fortes e Moraes (2016) e Melo, Fernandes e Oliveira (2017) que balizarão nosso estudo, utilizamos como juízo crítico para elege-los, pertencerem as discussões reformistas dos elementos essenciais conceituais e também a questão temporal, a partir do decálogo de 1900 indo-se embora em 1990. 
Nosso artigo está organizado em cinco itens, são eles: 1- Introdução, demarcado um sinótico temporalmente da instituição reformista federalista das ações políticas societais brasileiras, traça nossos objetivo, percurso metodológico e teórico; 2- Elemento essencial conceitual da descentralização, expressando a instituição conceitual deste; 3- Elemento essencial conceitual da autonomia federativa, explicitando o caminho instituinte do referido; 4Considerações finais, anunciando nossas apreensões objetivos sobre os elementos estudados e; 5- Referências, especificando os autores e seus textos que serviram de balizamento de nosso artigo.

\section{Elemento essencial conceitual da descentralização}

Com a recuperação dos alicerces difusos, no decálogo de 1980, dos entes estatais federativos brasileiros de comandos governativos ${ }^{5}$ centrais, intermediários e locais, com a redemocratização do país, principalmente com a retomada das eleições diretas populares para todos os níveis de comando governamentais, ainda com a descentralização fiscal teoricamente propagada pela Constituição Federal de 1988, alterando densamente as balizas de comando governamentais dos entes locais. A descentralização, de acordo com a teoria, se refere à repartição dos cargos administrativos para os níveis de comandos, desde o ente federativo central até o local, formando as mais diversificadas cessões de recursos e incumbências de colocações que admitem que um referido ente em comando exerça estratégias gestacionais de dadas ações estratégica políticas que independe de sua autonomia federativa política e fiscal (ARRETCHE, 2002).

No decálogo 1990, no Brasil, paulatinamente no início, as instituições políticas dos entes federativos prontamente permaneciam, de modo pleno, se reestruturando, primordialmente as ações estratégicas de políticas públicas sociais, porém, permaneciam centrada no comando governativo federativo central por intermédio da herança do regime militar (1964-1986), continuado assim, sob sua responsabilidade gestacional a ações de financiamento das políticas de saúde, habitação, merenda escolar, livro didático, assistência social, dentre outras (ARRETCHE, 2002).

Dentre as ações reformistas estatizantes das ações estratégicas, as políticas públicas societais, destacamos duas delas: a descentralização da política de saúde ao longo do decálogo de 1990 e a municipalização do ensino fundamental, em meio ao período de 1997 e 2000 . A

${ }^{5}$ Neste estudo, comandos governativos centrais refere-se ao Governo Federal, assim como intermediários Governo Estadual, bem como locais Governos Municipais.

Temas em Educ. e Saúde, Araraquara, v. 16, n. 1, p. 158-172, jan./jun., 2020. e-ISSN 2526-3471. 
primeira, demandada pelos embates vindouros do movimento de reforma sanitarista pro Sistema Único de Saúde (SUS), trazendo em seu arcabouço como marco principal a VIII Conferência Nacional de Saúde, em 1986, realizada em Brasília, Distrito Federal, antecedendo a CF/1988 (ARRETCHE, 2002).

O ente federativo de comando governativo central, teoricamente se consistiu num afortunado sucesso na transferência para os entes de comandos governativos intermediários e locais do país, repassando o comando gestacional da atenção básica à saúde, descentrando universalmente as ações de políticas públicas federativas de saúde e assim, seguidamente à constituição do SUS, emergiram como normatização constitucional com a CF/1988. Ainda que tal princípio da universalização de promoção aos serviços públicos de saúde calhasse a apresentar legitimidade, a municipalização dos serviços públicos de saúde, aludia um artifício de reedificação do arcabouço federativo do país de organicidade dos mesmos, de que balizaria recorrentemente a repassar ações que eram exercidas pelo ente de comando governativo de nível central para os entes intermediários e locais. Essa nova roupagem ficaria abancado no afastamento em meio ao financiamento e o aprovisionamento dos serviços, permanecendo o primeiro sobre a responsabilidade dos três entes federativos e o segundo sobre reponsabilidades dos entes locais (ARRETCHE, 2002).

Tal municipalização descentralizando universalmente a ações dos serviços de saúde perfez-se como artifício fundamental na agenda reformista do ente federativo de comando governativo central no setor da saúde ao extenso decálogo de 1990, arriscando a assegurar que, neste viés, o reformismo preponderou como um sucesso. Uma vez que na década 2000, 99\% dos entes de comando governativo locais permaneciam-se certificados no SUS, com contratualidades normatizadas pela política de descentralização do ente federativo de comando governativo central. Porque a agenda reformista visava universalizar a ascensão aos serviços e descontração gestacional. Porquanto a universalização dos serviços dar-se a entender a amplificação do esboço diretivos para os cidadãos, tendo em vista que o princípio contributivo do exemplar antecedente negava a ascensão as ações e serviços de saúde a uma classe expressiva da população, com pouca renda e com contornos prevaricados de inclusão mercadológica ao trabalho (ARRETCHE, 2002).

A contratualização dos entes federativos de comando governativo locais para adesão ao SUS, ficam explanado pela ação estratégica da descentralização do ente federativo de comando governativo central formalizadas em normativos constituídos por emissão do setor da Saúde, com publicação de Normas Operacionais Básicas no decálogo de 1990 (NOB/90), as quais foram: NOB/91, NOB/92, NOB/93 e NOB/96 (ARRETCHE, 2002). 
A NOB/91, a qual internar-se como abertura da habilitação ao SUS, normativa pela qual os entes federativos de comandos governativos intermediários e os locais proporcionariam a contratualização a adesão as ações estratégicas de políticas públicas societais de saúde para descentralização do ente federativo de comando governativo central, se submetendo às normatizações instituídas e certificando-se para acesso das transferências originárias do ente federativo de comando governativo central. Com isso, no período de 1991 e 1992, no comando governativo de Fernando Collor de Melo, aconteceu o elementar impulso de adesão, na perspectiva das NOB/91 e NOB/92, regulamentando sistematicamente as transferências de recursos aos entes de comando governativo intermediários e locais, regulando universalmente por intermédio do setor ministerial para as transferências de recursos, amortizando de tal modo as incertezas e politização das transferências ajustadas, apesar de que na prática, não se consolidar completamente motivados pelas crises políticas econômicas e instrucionais que levou a cassação do presidenciável na época (ARRETCHE, 2002).

Contudo, de 1993 e 1995, com a NOB/93, sob o comando do governante Itamar Franco. Em decorrência de um extenso procedimento de consulta, tal normativo ministerial ampliaria um ambiente opcional para os entes de comandos governativos locais, com tríades categóricas distintas de habilitação, respeitando assim, a potencialidade operacional existente no contexto de comando governativo local, com garantia de recursos para financiamento das referidas ações. Por ser um período marcado pelas incertezas econômicas do ente federativo de comando governativo central na execução integralista das transferências, motivados pela carência de recursos, aproximadamente 63\% dos entes locais aderiram ao SUS (ARRETCHE, 2002).

Contudo, aperfeiçoou-se o SUS com a NOB/96, em que sua execução tão-somente aconteceu dois anos depois de sua constituição, em1998, sob comando do governante Fernando Henrique Cardoso. Em que os contratos de adesão dos entes de comandos governativos locais superaram às metas do próprio ente ministerial do setor de comando governativo central da Saúde, por duplas motivações fundamentais, no caso da primeira, as inovações no regramento para as transferências de recursos dos entes federativos de comandos governativos centrais adicionavam recursos aos caixas de $66 \%$ dos entes federativos de comandos governativos locais do país e constituíam fiscalmente neutralidade para $22 \%$. Na segunda, o setor ministerial da saúde do ente federativo de comando governativo central convenceu de que as transferências dos recursos constituiriam exequibilidade concretizadas (ARRETCHE, 2002).

No setor educacional brasileiro, no período de 1997 e 2000, constitui-se a municipalização do ensino fundamental, com expressivo remanejamento das matrículas nesta etapa do ensino. Aumentando consideravelmente 6,7\% as matrículas totais no âmbito público, 
todavia que a nível do ente de comando governativo local acenderam-se 34,5\% e no ente de comando governativo intermediário ocorreu um decréscimo de $-12,4 \%$. Significando uma proeminente transferência das matrículas que eram ofertadas pelo comando estatal intermediário para os locais (ARRETCHE, 2002).

A referida CF/1988 expressa que a universalização das matrículas da etapa de ensino fundamental precisaria ser ofertada preferencialmente pelos entes federativos locais, constituindo ainda que os comandos governamentais intermediários e locais investissem $25 \%$ de suas receitas próprias dos impostos e de transferências no ensino. Expandindo sistematicamente pelos referidos entes federativos a universalização de acesso de matrículas em todas as etapas de ensino, tanto infantil, como fundamental, médio, assim como ainda, superior (ARRETCHE, 2002).

Tais receitas fiscais dos entes de comando governativo locais, provenientes das normas reformistas descentralizadoras, conexa a garantia constitucional vinculante de investimento no ensino, não apenas educacional, consentiram alargamento no investimento local direcionando assim a diversas ações afins, as quais são incentivo estudantil por intermédio de bolsas de auxílios e permanências, transporte escolar, merenda escolar, dentre outros (ARRETCHE, 2002).

O ente federativo ministerial educacional de comando governativo central, tendo agente do comando o presidenciável Fernando Henrique Cardoso, continha teoricamente, dentre diversos itens de sua agenda reformista, objetividade para a promoção municipal e a valorização da etapa de ensino fundamental, priorizando assim esta etapa de ensino, ainda que a mesma adviesse em detrimento de outras etapas de ensino, como também valorização dos proventos do corpo docente, fundamentalmente os que atuavam absolutamente docência em sala de aula na referida etapa de ensino (ARRETCHE, 2002).

Para isso, constitui-se burocraticamente uma Emenda Constitucional com previsão de uma década para os entes federativos de comandos governativos intermediários e locais, aplicarem o mínimo de $15 \%$ de todas as suas rendas tão-somente na etapa de ensino fundamental e, que ainda $60 \%$ destes, seriam investidos obrigatoriamente no provento docente efetivos na execução do magistério. Constituindo-se assim o custeio de discente anualmente, com suplementação pelo ente federativo de comando governativo central para o intermediário, considerando aqueles em que sua renda não atingisse o custeio estabelecido pela normatização constitucional. Com a Emenda Constitucional, a inusitada tática admissível para conservar as rendas locais gerou aumento considerável de universalização de acesso de matrículas na rede municipal para etapa de ensino fundamental. A descontração municipal derivou do arcabouço 
de estímulos legislativo respeitando em tese a disposição dos entes federativos de comando governativo mais locais (ARRETCHE, 2002).

Assim, as recentes regras reformistas constitucionais, acedem um arcabouço de estímulos perfazendo-se bem chamativo para a universalização de matrículas para a etapa de ensino fundamental, por se tornar uma oportunidade para proveitos de receita combinante com a expansão ofertante de serviços populacional e ainda valorização provençal para o corpo docente, ocasionando estruturação estimulante para a maior corrida para descentralização de comandos governativos locais, fundamentalmente das matrículas escolares (ARRETCHE, 2002).

A caracterização do elemento essencial conceitual da descentralização, incorporando as organizações das ações estratégicas das políticas educacionais e de saúde são diversas, na primeira, Novaes e Fialho (2010) afirmam que os elementos essenciais conceituais descentralização e democratização são empregados, em determinadas ocasiões, de configuração imbricada que não se assemelha a possuir alguma singularidade em meio aos dois. Semelhantemente calha, assim como se constituem analogias causal e decorrente dentre a descentralização e autonomia das ações estratégicas gestarias educacionais, quanto se o secundário consistisse em decorrência imprescindível do primário.

Outra semelhança é que, comumente, a descentralização possa ser proveniente e desenvolvida estruturalmente, organizações centralizadas, uma vez que uma determinada estrutura centralizada se vale de métodos de cessão de competência. A relação entre os elementos essências conceituais, centralização e descentralização, é tão embaraçosa que para caracterização da secundário se faz necessário que exista um artifício que afere estruturações políticos-administrativas aos entes de comandos governativos locais, com autonomia para constituir-se e decidir-se acerca das agendas de suas ações estratégicas nas políticas públicas respeitando-se a especificidades de caráter mais locais (NOVAES; FIALHO, 2010).

Considerando-se que exista um quádruplo de elementos essenciais conceituais de descentralização na América Latina, Caribe, os quais são: desconcentração, delegação, devolução e privatização. O primeiro se institui pela cessão ou incumbência de comando, de alçada de ação de comando governativo central para os intermediários e locais; O segundo, incide no comando governativo de determinados encargos atinentes de ações estratégicas de políticas públicas para um procurador paraestatal, no entanto, tais comandos, regulamentados pelo comando governativo centralizado. No caso do terceiro, se caracteriza fortalecendo autonomicamente os comandos governativos intermediários e locais, sem necessidade de controladoria diretiva do comando governativo central, incumbindo que tais comandos a 
responsabilização oferecendo ações e serviços, assim como, alçar recursos estruturais, tanto financeiros, como físicos, assim como humanos e pedagógicos imprescindíveis para às questões educacionais, aferindo competências ao comando governativo local elevado grau independente. O quarto e último, se distingui pela progressiva cessão de comando governativo das ações de políticas educativas, transformando as unidades escolares públicas em escolas particulares, perfazendo a privatização do acesso, permanência e sucesso escolar, se alimentando pela desigualdade societal (NOVAES; FIALHO, 2010).

Contudo, das distintas tipificações caracterizadas por Novaes e Fialho (2010) sobre o elemento essencial conceitual da descentralização, acreditamos que a devolução seria a mais ideal para construção da emancipação do comando governativo autonômico federativo estatal local. Tendo em vista, a elevada gradualidade independente que o comando governativo local abrange, tendo a possibilidade autônoma para instituição das ações participativa da sociedade cívico organizacional. Entretanto, os modelos de comandos governativos locais adotados na implantação do Programa Saúde da Escola, em Altamira, Pará hipoteticamente, aproxima-se mais do modelo de delegação, considerado que a as ações estratégicas de políticas públicas deste, jaziam acentuadas a priori, incumbindo ao comando governativo local tão-somente sua execução (NOVAES; FIALHO, 2010).

A descentralização democrática das ações estratégicas das políticas públicas educacionais poderiam ser materializadas por intermédio de cessões legislatória repassando os comandos governativos jurisdicionais centrais para os comandos governativos locais e seus entes interlocais, promovendo progressivamente, continuamente e abalizadamente dos arcabouços propriamente populacional dos entes mais locais, assim como os interlocais, especificamente os de domínio das políticas economicistas e societais (LIMA, 2015).

Contudo, os programas reformistas federalistas de descentralizações dos domínios do comando governativo central, tanto político organizacional, como administrativos das reestruturações que se estabeleceram na ação estratégica das políticas públicas dos sistemas educacionais das unidades escolares, se balizam visivelmente com maior protagonismo dos entes locais com adesão a referido programa, com contratação entre administrativamente por delegação de jurisdições, se ocasionando um processo de desconcentração da administração educacional, minimizando no decorrer dos últimos decálogos a conceituação do elemento essencial da descentralização democratizante ao símplice repasses de jurisdições (LIMA, 2015). 


\section{Elemento essencial conceitual da autonomia federativa}

O federalismo estatal é composto por configurações singulares verticalizadas com comando governativo desconjuntado, em que diversificadas modalidades governativas possuem poderes influentes na decisão dada a um determinado povo e sua jurisdição. Para tanto, nos comandos federativos estatais centrais, todos os comandos (central, intermediários e locais) independem-se dentre si e possuem soberanias em suas concernentes jurisdicionais, em decorrência que o poder local em que tal jurisdição é variável, de acordo com que se determina sua construção, respaldado pela soberania, o que se constitui como sujeitos politizados independentes com competências para efetivação de suas adequadas políticas. Tal soberania é derivada pelo voto direto populacional, apresentando autonomia ficais e que quase sempre, com propriedades militares, ainda apresenta no congresso federativo central, a presença de representatividade legislativa como ente federalista (ARRETCHE, 2002).

No Brasil, no decorrer do século XX os aglomerados reformistas objetivavam proporcionar aos entes federativos com maior eficiente e eficaz, objetando as pretensões almejadas pelo cidadão. Consistia na concepção estatizada societal, visando incrementar desenvolturas abotoadas à concorrência, equivalendo a um ente que valer-se-ia de aparelhos terceirizados que competiriam dentre si. A estatização social-liberal em contraponto a uma estatal social burocrático. Tais modificações implicavam em cidadãos inferiormente resguardados, mas ao mesmo tempo, com mais liberdade e politizados (OLIVEIRA; BARBOSA; FRANÇA, 2013).

Os entes federativos no contexto brasileiro vêm percorrendo um caminho concentrado, referente ao financiamento de suas ações estratégias das políticas públicas, com seus programas focados em conformidade com uma agenda preestabelecia pelo ente federalista central e tendente a alusão as redefinições estatais que inventaram uma inovação relacional a ação particular ou com entes públicos por intermédio de acordos gestacional com características empresarial no acolhimento às necessidades populacionais, como exemplo do ensino superior com a prática de programas focados que corroboram a coerência estatizada, assinalado na produção de maiores resultados envolvendo menores recursos (OLIVEIRA; BARBOSA; FRANÇA, 2013).

Com a publicação da CF/1988, que traz em seu arcabouço o ente federativo de comando governativo central que em uma direção, almeja autoridade na regulação do arrecadamento da receita e com moldes de repartição de tais receitas com contornos focados, advoga-se centralizado, contrapondo a autonomia de comando governativo dos entes locais. Contudo, em 
outra direção os comandos governativos dos entes locais vem emergindo com suas reivindicações por mais participação no domínio da elaboração das agendas e a coerente descentralização, já que a prática seguida pelo ente de comando governativo central está distante no que se refere as desigualdades socioeconômicas intermediárias e locais, ao avesso que os entes de comando governativos mais centralizados se apresentam com mais riquezas e cada vez mais ricos (OLIVEIRA; BARBOSA; FRANÇA, 2013).

Tal reforma estatista federalista é um artifício a ser inserido por meio de extenso embate, de configuração permanente, tendo em aspecto a volatilidade da circunstância economicista e societal sucedida no pais com marco iniciado pela CF/1988, contemplando o universo participativos dos entes federalistas estatais, perfazendo assim, uma pauta de discussões descentralizadoras dos recursos socioeconômicos, se balizando na alçada da prática das ações estratégicas das políticas públicas societais, caso o contrário, repetiremos a singela desconcentração financeira por meio de programas focados em ações determinada pelo comando governativo centralizado (OLIVEIRA; BARBOSA; FRANÇA, 2013).

A referida agenda reformista que é configurada nestes programas focais desconcentrados economicamente, proporcionou uma descentralização que nos modelos concretizados no país, alastrou espaços de trincheiras de batalhas tanto vertical, como horizontal, suscitando imprecisões sobre a assimilação identitária do ente federalista responsável pela execução das políticas societais como a saúde, a educação, a assistência social, a segurança, dentre outras. Tal inconclusas reformistas acarretaram apenas na falta de responsabilização do federalismo do comando governativo central diante dos distintos pleitos societários (OLIVEIRA; BARBOSA; FRANÇA, 2013).

Hostil constituam as instituições políticas de caráteres diversos, transpiram concomitantemente no contexto globalizado manifestando-se um certo estreitamento, pelo ajustamento e coordenação temporal, se exacerbando, proeminentemente, depois da desastrosa Segunda Guerra Mundial, em que o federalismo e a soberania popular democrática perfazem assentamentos na maior parte dos aparelhos astutos estatal. Nesse enquadramento, a socialização de variados regulamentos e a procura para ultrapassar as insígnias autoritárias homogêneas consistindo em ajustamento, de modo, com emersão das opiniões de tolerância, de consideração, de disparidade e, com destaque para remanejamento do domínio, numa perspectiva inclusiva. De tal modo, a baliza pluralista destacável quanto conceito essencial das intenções reguladoras de reorganização do aparato estatista (FORTES; MORAES, 2016).

Contanto, os rogados do democratismo assemelhar-se a assinalar a se rever elementos conceituais clássicos em que anteriormente ocupado pelo conhecimento politizado, de estilo a 
sinalizar as intenções de superação de velhos padrões, valorizando o conhecimento participativo manifesto, popularizado e do pluralismo de ideias. Quanto inovações das balizas do artifício politizado, tais intenções, certamente, impetram a reinserção espacial no contexto público, de caráter ao agenciamento ao ajuntamento em meio ao povoado e a competência de decidir-se (FORTES; MORAES, 2016).

A soberania popular democrática da atualidade estabeleceria "a participação substancial do sujeito", melhor dizendo, não somente do sujeito menos afastado que se restringe a admitir as disposições dos parlamentares, contudo qualquer sistematização em que lhe admita embate nos pontos influenciáveis, em um contexto politizado pluralista demandado e a distinção cultural dos sujeitos possam demandar em determinado artifício coerente e numa perspectiva inclusiva, no qual procederá em mais benfeitorias e o mais coeficiente de contentamento aos aglomerados setores. Tal ambiente público, como já visto, assemelhar-se ao da redoma mais local (FORTES; MORAES, 2016).

A autonomia federalista nota para os contextos dos entes sobre comandos governativos locais, a designação de um ambiente politizado para concretização democrática participativa, deliberativa numa perspectiva mais inclusiva, em que seja permita empoderamento popular com direito de oportunidade e de fala nas deliberações sobre as ações que envolvem seu entorno. Até mesmo porque, a descentralização estatal proporcionada pelo federalismo, ocasiona o estreitamento de laços entre os sujeitos públicos e o policiamento do sujeito popular, acostar-se dos aparatos que legisla e administra, em que aperfeiçoaria suscintamente artifícios a influência societal e a aplicabilidade qualitativa estatizada (FORTES; MORAES, 2016).

$\mathrm{Na}$ autonomia politizada federalista do ente governativo local proporcionaria a blindagem das agendas populistas democráticas pluralistas do ente governativo local, influenciando assim nas demandas nos arcabouços de culminação das agendas intermediárias que assim influenciariam na formação das agendas governativas do comando central, proporcionando o universo federalista estatista do nível central unificado, perfazendo-se assim, em quanto potencialidade estratégia advocatícia das minoridades nacionalistas (FORTES; MORAES, 2016).

Com isso, o aparelho federalista, holisticamente enxergado enquanto contorno de isolamento de competência, aumentaria os núcleos de se decidir, gerando determinada ciência de percalço ao autoritarismo, sendo que habitua a bancar sua presença no ceio societal como estatal de intensa centralização. Contanto, a potencialização do federalismo, enquanto organismo de agregação da distinção da união, poderá ser utilizado estrategicamente como mecanismo institucional e não institucional ao exercício para a cidadania, consentindo aos 
rogados preceitos democráticos da atualidade, com sustentabilidade na ação populista e no pluralismo politizado, anunciáveis na "autonomia político-comunitária do localismo federativo" (FORTES; MORAES, 2016, p. 223).

No setor das políticas públicas educacionais, com o seu processo de municipalização vindo do final do decálogo de 1980, com mais ênfase em 1990, instituindo com demandas dos movimentos políticos, sociais e sanitaristas, influenciando na inserção de direitos na Constituição Federal de 1988, acolhendo as exigências municipalistas destacando a adquirir a autonomia dos entes locais, na perspectiva do empoderamento e desafios para unidades federativas de comando governativo local, como ainda proveitos para ações estratégicas políticas educacionais, sendo que a os embates passam a existir balizados nas aberturas para a autonomia, democratização e a descentralização no dia-a-dia da unidade escolar. Como também, ocasionando aos entes federativos de comando governativo local a responsabilidade de instituição dos sistemas municipais de ensino, assim como os existentes nos entes governativos intermediário e local. (MELO; FERNANDES; OLIVEIRA, 2017).

Os referidos sistemas municipais que traziam no seio de suas instituições desafios a serem superados, tais como: "a criação de Conselhos Municipais de Educação, bem como outras instâncias para envolver a participação da sociedade civil na formulação dos projetos políticos pedagógicos e planos municipais de educação". Neste sentido, sendo imprescindível mais empenho dos gestores dos entes federativos locais na sua atuação e nos direcionamentos constituídos para a política educacional, como ponto de partida dos encargos que lhes são conferidas para as municipalidades. Sem falar, no gargalo em sistematização do acesso, permanecia e sucesso das etapas de ensino infantil e fundamental, que solicita qualificação na reestruturação, tanto física, como formação profissional com maior inserção financeira. De tal modo, propondose minimizar tais desafios, o ente federativo federal edificou programas para subsídio financeiro, alargando um regime de colaboração em meio aos entes federativos municipais, estaduais e o Distrito Federal. (MELO; FERNANDES; OLIVEIRA, p. 59, 2017).

\section{Considerações finais}

Com a consolidação institucionais dos entes federativos no começo do decálogo 1990, os advogados federalistas fiscais brasileiros confiavam na descontração fiscalista que consistiria fundamentalmente em tese para que a descentração das ações de políticas societárias prevalecesse. Contanto, na prática, até metade do referido decálogo, evidenciava que a referida distribuição de responsabilidades não era fidedigna, escassa, confusa e até mesmo nula. As analogias, em meio ao federalismo e descentralização, das ações políticas societárias não emergem homogêneas no meio de países federativos.

Temas em Educ. e Saúde, Araraquara, v. 16, n. 1, p. 158-172, jan./jun., 2020. e-ISSN 2526-3471. 
No nosso país, o Brasil, as ações de políticas societárias, compreendida teoricamente enquanto um comprometimento do comando governamental em prol do bem-estar essencial populacional, ainda não prevalece centralmente como estruturante legitimado nas ações políticas dos comandos governamentais locais. Motivados por este pretexto, a descentralização das ações políticas societárias acontece numa trincheira, debatida por créditos politizados entre os nivelamentos dos comandos governamentais, induzindo-os assim pelo ente federativo governamental central. Para tanto, nesta envergadura, a descentralização das ações políticas societárias, veio proveniente da junção de condições institucionais do ente federativo governamental central para estabelecer e executar programas de transferência de competências para os entes federativos governamentais locais.

Neste sentido, na governança sob o comando de presidente Fernando Henrique Cardoso, em tese, emerge o equilíbrio e a coerência burocratizantes nas ações societárias que consentiram que a agenda de descentralização se transforamaria em prática, por intermédio de projetos e programas múltiplos para inferências decisivas pelos entes federativos governamentais mais locais. Com destaque para retificações constitucionais, instrumentos normativos ministeriais, instituindo rigorosamente a efetuação das transferências federativas e, desfinanciamento das companhias públicas são atitudes diferenciadas de soluções e táticas praticadas pela governança federativa.

Contanto, numa prática mais democratizante descentralizada e respeitando à autonomia federalista dos comandos governativos intermediários e locais, destacamos os comandos governativos centrais do presidente Luiz Inácio Lula da Silva (2003-2006/2007-2010) e da presidenta Dilma Rousseff (2011-2014), em que foram instituídos diversificados projetos e programas envolvendo as ações políticas públicas educacionais e de saúde, como exemplo temos: o Programa de Erradicação do Trabalho Infantil (PETI), o Programa Agente Jovem de Desenvolvimento Social e Humano, o Programa Esporte e Lazer da Cidade (PELC), o Programa Bolsa Família (PBF), o Programa Mais Educação, o Programa Crack, é possível vencer, o Programa Brasil Sem Miséria”, o Programa Saúde na Escola (PSE), dentre outros.

\section{REFERÊNCIAS}

ALVES-MAZZOTI, Alda Judith; GEWANDSZNAJDER, Fernando. O método nas ciências naturais e sócias: pesquisas quantitativa e qualitativa. São Paulo: Pioneira, 1998 (1. ed.); 1999 (2. ed.); 2000 (1 $1^{\text {a }}$ reimpressão). 
ARRETCHE, Marta. Relações Federativas nas Políticas Sociais. Educ. Soc., Campinas, v. 23, n. 80, p. 25-48, set. 2002. Disponível em: http://www.cedes.unicamp.br. Acesso em: 01 jun. 2020.

BRASIL. Constituição (1988). Constituição da República Federativa do Brasil. Brasília, DF: Senado, 1988.

BRASIL. Lei n. 9.394, de 20 de dezembro de 1996. Lei de Diretrizes e Bases da Educação Nacional. Diário Oficial [da] República Federativa do Brasil, Brasília, DF, v. 143, n. 248, 23 dez. 1996.

DESLANDES, Suely Ferreira; GOMES, Romeu; MINAYO, Maria Cecília de Souza (Org.). Pesquisa social: método e criatividade. 28. ed. Petrópolis, RJ: Vozes, 2009.

FORTES, Gabriel Barroso; MORAES, Filomeno. Federalismo e democracia. RIL, Brasília, a. 53, n. 211, p. 199-226, jul./set. 2016.

LIMA, C. Licínio. O programa "Aproximar Educação", os municípios e as escolas: descentralização democrática ou desconcentração administrativa? Questões Atuais de Direitos Locais. Associação de Estudos de Direito Regional e Local, Braga, n. 5, jan./mar. 2015.

MELO, Maria de Fátima da Silva; FERNANDES, Sheila Beatriz da Silva; OLIVEIRA, Francisca de Fátima Araújo. Federalismo, descentralização e municipalização: desafios das políticas públicas para a gestão educacional. HOLOS, Ano 33, v. 03, 2017.

NOVAES, Ivan Luiz; FIALHO, Nadia Hage. Descentralização educacional: características e perspectivas. RBPAE, v. 26, n. 3, p. 586-602, set./dez. 2010.

OLIVEIRA, Edmilson Jovino de; BARBOSA, Janaina Lopes; FRANÇA, Magna. A Reforma do Estado Brasileiro e a Descentralização: implicações do federalismo fiscal nos estados e municípios. Revista Educação e Políticas em Debate, v. 2, n. 2, p. 405-416, jul./dez. 2013.

\section{Como referenciar este artigo}

BANDEIRA, Marconde Ávila; OLIVEIRA, Ney Cristina Monteiro; MILÉO, Irlanda do Socorro de Oliveira. Programa Saúde na Escola: descentralização e respeito à autonomia federativa. Temas em Educ. e Saúde, Araraquara, v. 16, n. 1, p. 158-172, jan./jun., 2020. eISSN 2526-3471. DOI: https://doi.org/10.26673/tes.v16i1.13921

Submetido em: 20/01/2020

Revisões requeridas: $28 / 03 / 2020$

Aprovado em: 26/05/2020

Publicado em: 19/06/2020 